\section{Current evidence of antifungal prophylaxis and therapy in pediatric patients}

\author{
Mareva Giacchino, 1 \\ Giuseppe Maria Milano,2 \\ Francesca Carraro, 1 Stefania Bezzio, \\ Anna Pegoraro, ${ }^{3}$ Franco Aversa, 2 \\ Simone Cesaro 3 \\ 1Pediatric Hematology Oncology and \\ Bone Marrow Unit, Ospedale Infantile \\ Regina Margherita, Torino; 2Pediatric \\ Oncohematology and Bone Marrow Unit, \\ Azienda Ospedaliera di Perugia; \\ 3Pediatric Hematology Oncology, Azienda \\ Ospedaliera Universitaria Integrata, \\ Verona, Italy
}

\section{Abstract}

Invasive fungal infections (IFI) are an important complication in pediatric haematological and oncological patients who undergo intensive chemotherapy for leukemia, solid tumour at advanced stage or relapsed, and hematopoietic stem cell transplantation. The incidence of IFI is lower than bacterial infection but mortality rate remains high. This review is designed to help paediatric oncologists in choosing the appropriate anti-fungal strategy and agents for prophylaxis, empirical, pre-emptive and specific therapy on the basis of published evidence.

\section{Introduction}

Despite the advent of advanced anti-fungal agents, invasive fungal infections (IFI) remain a major cause of morbidity and mortality in neutropenic cancer patients. Risk classes are well stratified for adult patients but not for children. ${ }^{1}$ In a recent prospective survey of Italian Association of Pediatric Hematology Oncology (AIEOP) showed that IFI were more frequent in pediatric patients with acute myeloid leukaemia (AML) during induction therapy, acute lymphoblastic leukaemia (ALL), relapsing non-Hodgkin Lymphoma (NHL) and advanced stage or relapsing solid tumours. ${ }^{2}$

\section{Prophylaxis, empirical and pre-emptive therapy}

Few data are available in paediatric patients. In epidemiological reports on children the incidence of IFI ranged from 5-13\% with a peak of up to $24 \%$ in AML patients. Yeast infections have represented for several decades the prevalent etiology of proven IFI but in recent years invasive aspergillosis (IA) is continuously increasing.,3 Mortality rates remains high, with IA-related mortality ranging from $33-55.6 \% .3,4$ Given this mortality rate, behavioural measures strategies such as cooking food, washing hands, wearing face masks and using HEPA filters are needed to prevent the risk of developing IFI. Recommendations for adult patients have been recently issued by leading scientific societies without covering the pediatric aerea. ${ }^{5-7}$

In adult patients, meta-analyses indicated that anti-fungal prophylaxis significantly reduced the incidence of IFI but not the overall mortality. A randomised controlled study reported that prophylaxis with posaconazole significantly reduced the incidence of proven and probable IFI in patients with AML. ${ }^{8}$

Regarding empirical therapy a recent metaanalysis indicated that this strategy reduced significantly the incidence of proven and probable IFI in neutropenic patients but it was not able to reduce overall mortality. ${ }^{9}$ The comparison of different anti-fungal agent used empirically, particularly azoles vs liposomal Amphotericin B, did not show any difference in efficacy or mortality.

To minimise prescription of unnecessary anti-fungal agents every diagnostic efforts should tried before. In the neutropenic adult patients, Maertens et al., ${ }^{10}$ observed that a preemptive strategy, based on daily serum galactomannan antigenemia testing, computed tomography (CT) scan, and bronchoalveolar lavage reduced anti-fungal treatment by $78 \%$ compared with empirical therapy without affecting negatively survival. This approach is feasible for IA but not studied adequately so far for zygomycetes.

Only one study ${ }^{11}$ compared pre-emptive and empirical strategies. The pre-emptive approach was associated with a significantly greater incidence of IFI, particularly in patients with acute leukemia in induction, but it had no impact upon overall mortality. The study by Girmenia et al., ${ }^{12}$ which was based on an intensive diagnostic work-up that included a daily galactomannan test for 3 consecutive days and a chest CT scan, reported the preemptive approach was associated with a $43 \%$ reduction in anti-fungal agents compared with the empirical. There was no undue delay in starting therapy and a $63 \%$ survival rate was achieved in patients with IFI

In children the level of evidence for the use of antifungal drugs is inferior than the adults because the published data are limited and based mainly on retrospective studies or on studies of pharmacokinetic; moreover, the antifungal drugs marketed recently have no paediatric indication (posaconazole, anidulafungin), or have an indication narrower than the in vitro activity of the molecule (micafun-
Correspondence: Mareva Giacchino, Pediatric Hematology Oncology and Bone Marrow Unit, Regina Margherita Pediatric Hospital, P.za Polonia 94, 10126, Torino, Italy.

Tel. +39.011.3135222 - Fax: +39.011.3135452

E-mail: mareva.giacchino@unito.it

Key words: fungal infection, pediatric malignancy.

Acknowledgement: the authors would like to thank Dr G A Boyd for editing this paper.

Received for publication: 13 December 2010

Revision received: 3 March 2011.

Accepted for publication: 10 March 2011.

This work is licensed under a Creative Commons Attribution 3.0 License (by-nc 3.0)

(C) Copyright M. Giacchino et al., 2011

Licensee PAGEPress, Italy

Pediatric Reports 2011; 3:e6

doi:10.4081/pr.2011.e6

gin). Consequently, differently from adults, no specific guidelines are available for IFI in children. We performed a literature search with the aim assess the level of evidence for the use of antifungal drugs in paediatric patients affected by IFI. The key words used for the selection of the studies were antifungal prophylaxis, antifungal empiric therapy, antifungal pre-emptive therapy, antifungal therapy, fungal infections, and pediatric malignancy. The literature search was limited to English language papers and the period analyzed was from 1 January 1990 to 31 July 2010. Reference list of papers selected by literature search was also used as source, if necessary. The results of the search were first discussed and scored by the authors and then presented for the final discussion and approval to an expert meeting held in Florence on 12 and 13 October 2010 where the representatives of centers belonging to Italian Association of Paediatric Hematology Oncology (AIEOP) attended. The scoring system proposed by Infectious Diseases Society of America was adopted to define the quality of evidence and strength of recommendations.

Table 1 summarizes the published studies on antifungal prophylaxis. Most studies were retrospective or phase II with a limited sample size. Moreover, the only randomised study ${ }^{13}$ with a large cohort of patients, dating back to 1994, did not satisfy current EORTC criteria for fungi classification. Overall, the studies on prophylaxis were scored as $\mathrm{C}$ with an evidence level of between II and III. The need of prophylaxis is still debated and depends on the type of patients managed (high-risk vs. low-risk), local incidence of IFI, type of fungi isolated, attitude of the centre to intensive diagnostic work-up in case of IFI is suspected, and finan- 
cial resources. We concluded that no strong recommendation is possible for antifungal prophylaxis in pediatric patients. However, It should be considered for all high risk patients such as AML during induction, acute leukaemia and NHL in relapse, advanced stage or relapsing solid tumours when local epidemiology data show an incidence of IFI higher than usually reported in other centres or higher than in a recent past. The antifungal drugs most commonly used and resulted safe and active, in analyzed studies, were fluconazole and itraconazole, liposomal amphotericin-B, and recently micafungin. The determination of blood level is recommended when itraconazole or other azoles are used. ${ }^{5}$

Differently from prophylaxis, the empiric use of antifungal drugs has been investigated in prospective controlled randomized studies. In a multi-centre, randomised study recruiting adults and children Prentice ${ }^{14}$ reported that liposomal amphotericin B was more efficacious than standard amphotericin $B$ in patients with fever of unknown origin (FUO). In a double-blind multi-center study Maertens et al. ${ }^{15}$ showed that caspofungin was not inferior to liposomal amphotericin B in children. A recent prospective, randomised, controlled study by Italian Association of Pediatric Hematology Oncology (AIEOP) that evaluated the empiric antifungal therapy in patients at low and high-risk of IFI reported that no significant differences in the tolerability and efficacy of liposomal amphotericin B and caspofungin (Caselli D., personal communication). Moreover, in the low-risk arm the patients were randomised to three different treatment i.e. caspofungin vs. liposomal amphotericin B vs. no antifungal therapy. Success rate and 30day survival resulted similar in all three arms, suggesting that the use of empiric antifungal treatment is no more fundamental in this category of patients.

We concluded that empiric antifungal therapy has a level of evidence of BII in high-risk patients. Liposomal amphotericin B and caspofungin are the recommended drugs. In the lowrisk patients, this strategy is not of proven efficacy and should be discouraged, while a careful diagnostic work-up is recommended

Pre-emptive treatment is the new frontier of early antifungal therapy because has the potential for reducing unnecessary antifungal therapy given empirically on the basis of a persisting neutropenic fever refractory to antibiotic treatment. The adoption of a pre-emptive strategy needs a prompt diagnostic evaluation with CT scan, galactomannan antigen, and 1-3 $\beta$-D-glucan antigen, as well as the performing of brochoalveolar lavage (BAL). This diagnostic panel may be difficult to perform in children for several reasons. CT may need sedation in younger children, may increase the exposure to radiation in case of repeated exams, or fre-
Table 1. Summary of the main evidence-based indications for invasive fungal infections therapy in immunocompromised patients.

\begin{tabular}{|c|c|c|c|c|}
\hline Authors & $\begin{array}{l}\text { Patients } \\
\text { number }\end{array}$ & $\begin{array}{l}\text { Antifungal } \\
\text { prophylaxis }\end{array}$ & Results & Grading \\
\hline Cáp J, 1993 & 22 & Fluconazole $1-4 \mathrm{mg} / \mathrm{kg} / \mathrm{die}$ & IFI: 2 proven (9\%) & C III \\
\hline $\begin{array}{l}\text { Ninane J, } \\
1994\end{array}$ & 502 & $\begin{array}{l}\text { Fluconazole } 3 \mathrm{mg} / \mathrm{kg} \text { vs } \\
\text { Nystatin } 50.000 \mathrm{U} / \mathrm{kg} \text { or oral }\end{array}$ & $\begin{array}{l}\text { IFI: } 2.1 \% \text { in Fluconazole group; } \\
8.4 \% \text { in Amphotericin B group } \\
\text { Amphotericin B } 25 \text { mg/kg/die }\end{array}$ & C II \\
\hline $\begin{array}{l}\text { Uhlenbrock S, } \\
2001\end{array}$ & 29 & $\begin{array}{l}\text { Liposomal Amphotericin B } \\
1 \mathrm{mg} / \mathrm{Kg} 2 \text { times/week vs early } \\
\text { intervention }\end{array}$ & $\begin{array}{l}\text { IFI: } \\
5 \text { probable; } \\
1 \text { possible; } \\
\text { no differences between } 2 \text { groups }\end{array}$ & C III \\
\hline Simon A, 2006 & 39 & Itraconazole $6-8 \mathrm{mg} / \mathrm{kg} / \mathrm{die}$ & IFI: 0 & C III \\
\hline Hovi L, 2007 & 98 & $\begin{array}{l}\text { Itraconazole } 5 \mathrm{mg} / \mathrm{kg} / \mathrm{die} \\
\text { or Fluconazole } 5-8 \mathrm{mg} / \mathrm{kg} / \mathrm{die} \\
\text { if toxicity }\end{array}$ & $\begin{array}{l}117 \text { febrile episodes; } \\
\text { IFI: } 2 \text { proven; } \\
27 \text { possible }\end{array}$ & C II \\
\hline Kolve H, 2009 & 84 & Liposomal Amphotericin B & $\begin{array}{l}\text { Successfull: } \\
\text { 96.8\% prophylaxis } \\
\text { 87.9\% empirical therapy }\end{array}$ & C III \\
\hline Kaya Z, 2009 & 154 & Fluconazole $4-6 \mathrm{mg} / \mathrm{kg} / \mathrm{die}$ & $\begin{array}{l}\text { IFI: } \\
11 \text { proven }(7,2 \%) ; \\
4 \text { probable }(2,6 \%) ; \\
6 \text { possible }(3,8 \%)\end{array}$ & C III \\
\hline Kusuki S, 2009 & 40 & Micafungin $3 \mathrm{mg} / \mathrm{kg} / \mathrm{die}$ & $\begin{array}{l}\text { IFI: } \\
1 \text { proven; } \\
0 \text { possible/probable; } \\
10 \text { suspected }\end{array}$ & C III \\
\hline $\begin{array}{l}\text { Kobayashi R, } \\
2010\end{array}$ & 22 & Itraconazole $5 \mathrm{mgl} / \mathrm{kg} / \mathrm{die}$ & $\begin{array}{l}\text { IFI: } \\
1 \text { possible; } \\
0 \text { proven/probable }\end{array}$ & C II \\
\hline
\end{tabular}

Table 2. Summary of the main evidence-based indications for invasive fungal infections therapy in immunocompromised patients.

\begin{tabular}{|c|c|c|c|c|}
\hline Drug & $\begin{array}{l}\text { IA } \\
\text { 1st line therapy }\end{array}$ & $\begin{array}{c}\text { IA } \\
2^{\text {nd }} \text { line therapy }\end{array}$ & Candidiasis & Rare mycosis \\
\hline Liposomal amphotericin B & B II & BII & BII & BII \\
\hline Micafungin & NE & CII & $\mathrm{BI}$ & $\mathrm{NE}$ \\
\hline Caspofungin & CII & BII & BII & $\mathrm{NE}$ \\
\hline Voriconazole & BII & BII & BII & BII \\
\hline Posaconazole & NE & CIII & CIII & CIII \\
\hline Combination therapy & CIII & CII & CIII & CIII \\
\hline
\end{tabular}

IA, invasive aspergillosis; $\mathrm{NE}$, no evidence.

Table 3. Dosage and label use of the common antifungal drugs.

\begin{tabular}{lll} 
Antifungal agent & Authorized age group & Recommended dose \\
L-AmB & Licensed in children & $1-5 \mathrm{mg} / \mathrm{kg} / \mathrm{d}$ i.v. \\
& No age range specified & \\
Voriconazole & $>2$ years & $2-12 \mathrm{yrs}: 7 \mathrm{mg} / \mathrm{kg}$ every $12 \mathrm{~h}$ i.v. \\
& & Or $200 \mathrm{mg}$ twice daily p.o. \\
& $12-18 \mathrm{yrs}: 6 \mathrm{mg} / \mathrm{kg}$ every 12 h i.v. \\
& Or $100-200 \mathrm{mg} \times 2 \mathrm{p} .0$. \\
\hline Posaconazole & $>18$ years & $600-800 \mathrm{mg} /$ day \\
Caspofungin & No licence for children as yet & $2-18 \mathrm{yrs}: 50 \mathrm{mg} / \mathrm{mq}$ daily i.v. loading \\
& Licensed for use in children & dose $70 \mathrm{mg} / \mathrm{mq}$ \\
\hline Micafungin & Neonates to adults & $2 \mathrm{mg} / \mathrm{Kg} / \mathrm{d} \mathrm{or} 100 \mathrm{mg} /$ day i.v. $>40 \mathrm{Kg}$ \\
\hline
\end{tabular}

D-Amb: Amphotericin deossicolato; L-AMB: liposomal Amphotericin 
quently may results in a specific sign. Burgos et al. reported that nodules and a specific infiltrates were the most common findings in children and, differently from adults, halo sign was detected in only $6.5 \%$ of children with IA. ${ }^{4}$ Serum fungal antigen tests may be useful for the diagnosis of IA in pediatric cancer patients. The performance of serum galactomannan antigen has been show to be good in children as in adults with regard to specificity and NPV (negative predictive value). The less sentivity of the test than adult patients could be attributed to a high incidence of false positives due to the type of diet, the cross-reactivity with $\beta$-lactamic antibiotics commonly used in children (penicillin, acid clavulanic/amoxicillin), and cross-reactions with Bifidobacteria lipoteic acid in intestinal micro-flora. ${ }^{16,17}$ Moreover, there is less experience of testing galactomannan antigen in children who performed a BAL. Scarce information is available on the use of 1-3 $\beta$-D-glucan in children.

Altogether, we concluded that pre-emptive therapy strategy, though a valid option, has been not investigated adequately in the pediatric patients so it is not possible to formulate any recommendation on it. Therefore, prospective study are needed.

\section{Therapy for probable/proven mycosis}

Although prospective phase III studies are almost lacking in children, several retrospective, case-control, or prospective phase II studies have been published on proven/probable IFI in children. Table 2 and 3 summarize the level of evidence for the single drugs in different setting (first line IA, second line IA, candidiasis, non-Aspergillus mould infection) and the recommended dosage.

\section{Polyenes}

Liposomal amphotericin B has a broad-spectrum activity against the most common yeast and mould species, while Aspergillus terreus, Aspergillus versicolor, Aspergillus flavus (some), Scedosporium and Candida lusitaniae are reported to be resistant.

Liposomal amphotericin B was scored as BII for the first and second line treatment of IA, BI for invasive candidiasis, and BIII for nonaspergillus mould infections. ${ }^{18-21}$

\section{Azoles}

Triazoles are a class of drugs with a narrower spectrum of action and less toxicity than amphotericin B. Voriconazole is licensed for children over 2 years old. It was scored BII both for IA, candidiasis, and invasive infections by Scedosporium and Fusarium. The use of voriconazole as targeted therapy in children was investigated by Walsh, 22 in 58 patients who reported $42 \%$ complete and partial responses and $7 \%$ disease stabilization. Cesaro ${ }^{23}$ and Yilmaz $^{24}$ achieved similar results in a total of 34 patients with refractory IA. Recently, the therapeutic drug monitoring has been suggested to optimize the efficacy and prevent toxicity. In fact, voriconazole has many interactions with other drugs that may influence its escretion and require the modulation of the daily dose. Posaconazole (PSZ), a second generation azole, has a spectrum of activity even broader than voriconazole, being active also against zygomycetes, and a better safety profile. The published data on pediatric use are limited to 3 studies ${ }^{25-27}$ one assessed the pharmacokinetic in a group of patients of 8-12 yearold, one described the clinical response in 12 patients treated as salvage therapy and the last one evaluated the clinical response on 15 pediatric patients with proven/probable infections. This last study reported an efficacy rate of $57 \%$ against zygomycetes, $75 \%$ against moulds, $50 \%$ against Aspergillus and 50\% against candida strains. ${ }^{26}$ Considering that posaconazole is currently not indicated for the pediatric age and the limited data available, we scored it as CIII, both for IA, candidiasis, and other mould infections.

\section{Echinocandins}

This new class of drugs inhibits membrane beta 1,3 D-glucan and in fact blocks membrane formation and stabilisation. Efficacy and toxicity profiles are excellent although some strains of candida (Candida guilliermondii and parapsilosis) and rare fungi (Zygomycetes, Cryptococcus, Trichosporon, Fusarium, Scedosporium) intrinsincally less sensitive or even resistant. Caspofungin, the first of this new class of drugs, is associated with rare drug-drug interactions. One multi-centre study reported an $81 \%$ success rate of caspofungin as first-line therapy against documented candida infections and a $50 \%$ success rate as rescue therapy for IA. ${ }^{28}$ We scored caspofungin as BII for the therapy of Candida and CII for the therapy of IA Micafungin, which was approved as first-line therapy against invasive and oropharyngeal candidiasis in the newborn and older children, was recently introduced into clinical onco-haematology practice. Micafungin resulted non inferior to liposomal amphotericin B in a recent prospective randomized study on invasive candidiasis. ${ }^{29}$ Moreover, Denning et al. found a response rate of $50 \%$ to micafungin used alone or in combination with other antifungal drugs for IA. ${ }^{30}$ We scored micafungin as BII for invasive candidiasis and CII for IA.

\section{Combination therapy}

Combination therapy (particularly polyenes and azoles or polyenes plus echinocandins) is used in several paediatric centres. Drug combinations are hypothesized to exert a synergic action because different mechanisms of action on the fungal cell are exploited, the spectrum of action is widened and complementary pharmacokinetic and dynamic properties come into play. Most of reports on combination therapy are retrospective ${ }^{2-4,31,32}$ and showed that this strategy is safe and active both for IA, candidiasis, and other mould infection but evidence of superior efficacy than monotherapy has been found so far. Considering the higher costs, combination therapy is optional and a matter of further investigation, we scored its use as CII as second line treatment for IA and CIII for all other infections.

In attempting to orientate paediatric oncologists in appropriate choice of anti-fungal agents for their patients, the evidence provided in this review leads to the conclusion that the risks, benefits and costs of modern antifungal therapy in children need to be carefully weighed up, given the state of the art in adults and the few reports in paediatric patients.

\section{References}

1. Maertens J. Evaluating prophylaxis of invasive fungal infections in patients with haematologic malignancies. Eur J Haematol 2007;78:275-82.

2. Castagnola E, Cesaro S, Giacchino M, et al. Fungal infections in children with cancer: a prospective, multicenter surveillance study. Pediatr Infect Dis J 2006;25:634-9.

3. Hale KA, Shaw PJ, Dalla-Pozza L, et al. Epidemiology of paediatric invasive fungal infections and a case-control study of risk factors in acute leukaemia or post stem cell transplant. Br J Haematol 2010;149: 263-72.

4. Burgos A, Zaoutis TE, Dvorak CC, et al. Pediatric invasive aspergillosis: a multicenter retrospective analysis of 139 contemporary cases. Pediatrics 2008;121: e1286-94.

5. Maertens J, Marchetti 0, Herbrecht R, et al. European guidelines for antifungal management in leukemia and hematopoietic stem cell transplant recipients: summary of the ECIL 3-2009 Update. Bone Marrow Transplant 2010;Jul 26. [Epub ahead of print].

6. Walsh TJ, Anaissie EJ, Denning DW, et al. Treatment of aspergillosis: clinical practice guidelines of the Infectious Diseases Society of America. Clin Infect Dis 2008; 46:327-60.

7. Guidelines on the management of invasive fungal infection during therapy for haematological malignancy. 2008. Available at www.bcshguidelines.com

8. Cornely OA, Maertens J, Winston DJ et al. Posaconazole vs. fluconazole or itraconazole prophylaxis in patients with neutrope- 
nia. N Engl J Med 2007;356:348-59.

9. Goldberg E, Gafter-Gvili A, Robenshtok E, et al. Empirical antifungal therapy for patients with neutropenia and persistent fever: Systematic review and meta-analysis. Eur J Cancer 2008;44:2192-203.

10. Maertens J, Theunissen K, Verhoef G, et al. Galactomannan and computed tomography-based preemptive antifungal therapy in neutropenic patients at high risk for invasive fungal infection: a prospective feasibility study. Clin Infect Dis 2005;41: 1242-50.

11. Cordonnier C, Pautas C, Maury S, et al. Empirical versus preemptive antifungal therapy for high-risk, febrile, neutropenic patients: a randomized, controlled trial. Clin Infect Dis 2009;48:1042-51.

12. Girmenia C, Micozzi A, Gentile G, et al. Clinically driven diagnostic antifungal approach in neutropenic patients: a prospective feasibility study. J Clin Oncol 2010;28:667-74.

13. Ninane J. A multicentre study of fluconazole versus oral polyenes in the prevention of fungal infection in children with hematological or oncological malignancies. Multicentre Study Group. Eur J Clin Microbiol Infect Dis 1994;13:330-7.

14. Prentice HG, Hann IM, Herbrecht R, et al. A randomized comparison of liposomal versus conventional amphotericin B for the treatment of pyrexia of unknown origin in neutropenic patients. Br J Haematol 1997;98:711-8.

15. Maertens JA, Madero L, Reilly AF, et al. A randomized, double-blind, multicenter study of caspofungin versus liposomal amphotericin B for empiric antifungal therapy in pediatric patients with persistent fever and neutropenia. Pediatr Infect Dis J 2010;29:415-20.

16. Thomas L, Baggen L, Chisholm J, Sharland M. Diagnosis and treatment of aspergillosis in children. Expert Rev Anti Infect Ther 2009;7:461-72.
17. Castagnola E, Furfaro E, Caviglia I, et al. Performance of the galactomannan antigen detection test in the diagnosis of invasive aspergillosis in children with cancer or undergoing haemopoietic stem cell transplantation. Clin Microbiol Infect 2010;16:1197-203.

18. Ringdén 0, Andström EE, Remberger M, et al. Prophylaxis and therapy using liposomal amphotericin B (AmBisome) for invasive fungal infections in children undergoing organ or allogeneic bone-marrow transplantation. Pediatr Transplant 1997; 1:124-9.

19. Konja J, Glavas B, Anicic. Experience with liposomal amphotericin B at the Hematology-Oncology Department Children's Hospital Salata Medical School, University of Zagreb. Acta Biomed 2006;77:14-6.

20. Dehority W, Willert J, Pong A. Zygomycetes infections in pediatric hematology oncology patients: a case series and review of the literature. J Pediatr Hematol Oncol 2009 ;31:911-9.

21. Kolve H, Ahlke E, Fegeler W, et al. Safety, tolerance and outcome of treatment with liposomal amphotericin B in paediatric patients with cancer undergoing hematopoietic stem cell transplantation. J Antimicrob Chemother 2009;64:383-7.

22. Walsh TJ, Lutsar I, Driscoll T, et al. Voriconazole in the treatment of aspergillosis, scedosporiosis and other invasive fungal infections in children. Pediatr Infect Dis J 2002;21:240-8.

23. Cesaro S, Strugo L, Alaggio R, et al. Voriconazole for invasive aspergillosis in oncohematological patients: a single-center pediatric experience. Support Care Cancer. 2003;11:722-3.

24. Yilmaz D, Balkan C, Ay Y, et al. A rescue therapy with a combination of caspofungin and liposomal amphotericin B or voriconazole in children with haematological malignancy and refractory invasive fungal infections. Mycoses. 2009 Nov 10. [Epub ahead of print]

25. Krishna G, Sansone-Parsons A, Martinho $\mathrm{M}$, et al. Posaconazole plasma concentrations in juvenile patients with invasive fungal infection. Antimicrob Agents Chemother 2007:51:812-8.

26. Cesaro S, Milano GM, Aversa F. Retrospective survey on the off-label use of posaconazole in pediatric hematology patients. Letter to editor. Eur J Clin Microbiol Infect Dis 2010 Dec 1. [Epub ahead of print]

27. Lehrnbecher T, Attarbaschi A, Duerken M, et al. Posaconazole salvage treatment in paediatric patients: a multicentre survey. Eur J Clin Microbiol Infect Dis 2010;29: 1043-5.

28. Zaoutis TE, Jafri HS, Huang LM, et al. A retrospective, multicenter study of caspofungin for the treatment of documented Candida or Aspergillus infections in pediatric patients. Pediatrics 2009;123:877-84.

29. Kuse ER, Chetchotisakd P, Da Cunha CA, et al. Micafungin Invasive Candidiasis Working Group. Micafungin versus liposomal amphotericin B for candidaemia and invasive candidosis: a phase III randomised double-blind trial. Lancet 2007; 369:1519-2.

30. Denning DW, Marr KA, Lau WM, et al. Micafungin (FK463), alone or in combination with other systemic antifungal agents, for the treatment of acute invasive aspergillosis. J Infect 2006;53:337-49.

31. Cesaro S, Giacchino M, Locatelli F, et al. Safety and efficacy of a caspofungin-based combination therapy for treatment of proven or probable Aspergillosis in pediatric hematological patients. BMC Infectious Diseases 2007;7:28.

32. Cesaro S, Toffolutti T, Messina C, et al. Safety and efficacy of caspofungin and liposomal amphotericin B, followed by voriconazole in young patients affected by refractory invasive mycosis. Eur J Haematol 2004;73:50-5. 